\title{
Irregular Intuitionistic fuzzy graph
}

\author{
${ }^{1}$ A.Nagoor Gani, ${ }^{2}$ R. Jahir Hussain, ${ }^{3}$ S. Yahya Mohamed \\ ${ }^{1,2}$ P.G and Research Department of Mathematics, Jamal Mohamed College, Tiruchirappalli-620 020, India \\ ${ }^{3}$ Department of Mathematics, Govt. Arts College, Tiruchirappalli-620 022, India
}

Abstract: In this paper, some types of Irregular intuitionistic fuzzy graphs and properties of neighbourly irregular, highly irregular intuitionistic fuzzy graphs are studied. Some results on totally Irregular intuitionistic fuzzy graphs are established.

Keywords: Intuitionistic fuzzy graph, degree, total degree, Intuitionistic fuzzy sub graph. 2010Mathematics Subject Classification: 03E72, 03F55

\section{Introduction:}

Atanassov [1] introduced the concept of intuitionistic fuzzy (IF) relations and intuitionistic fuzzy graphs (IFGs). Research on the theory of intuitionistic fuzzy sets (IFSs) has been witnessing an exponential growth in Mathematics and its applications. This ranges from traditional Mathematics to Information Sciences. This leads to consider IFGs and their applications. R. Parvathy and M.G.Karunambigai's paper [5] introduced the concept of IFG and analyzed its components. A. Nagoor Gani and S.R. Latha[3] introduced Irregular fuzzy graphs and discussed some of its properties.

In this paper, some properties of Irregular Intuitionistic fuzzy graphs and neighbourly irregular intuitionistic fuzzy graphs are studied. Also Some results on totally Irregular intuitionistic fuzzy graphs are established.

\section{Preliminary}

Definition 2.1: A fuzzy graph $\mathrm{G}=(\sigma, \mu)$ is a pair of functions $\sigma: \mathrm{V} \rightarrow[0,1]$ and $\mu: \mathrm{V} \times \mathrm{V} \rightarrow[0,1]$, where for all $\mathrm{u}, \mathrm{v} \in \square \mathrm{V}$, we have $\mu(\mathrm{u}, \mathrm{v}) \leq \sigma(\mathrm{u}) \Lambda \sigma(\mathrm{v})$.

Definition 2.2: The fuzzy subgraph $H=(\tau, \rho)$ is called a fuzzy subgraph of $G=(\sigma, \mu)$ if $\tau(\mathrm{u}) \leq \sigma(\mathrm{u})$ for all $\mathrm{u} \mathrm{C} \square \mathrm{V}$ and $\rho(\mathrm{u}, \mathrm{v}) \leq \mu(\mathrm{u}, \mathrm{v})$ for all $\mathrm{u}, \mathrm{v} \mathrm{C} \square \mathrm{V}$.

Definition 2.3: Let $G=(\sigma, \mu)$ be a fuzzy graph. The degree of a vertex $v$ is $d(v)=\Sigma u \neq v \mu(v, u)$

Definition 2.4: Let $G=(\sigma, \mu)$ be a fuzzy graph on $G *:\langle V, E\rangle$. If $d_{G}(v)=k$ for all $v \in V$, i.e., if each vertex has the same degree $\mathrm{k}$, then $\mathrm{G}$ is said to be a regular fuzzy graph of degree $\mathrm{k}$ or a k-regular fuzzy graph.

Definition 2.5: Let $G=(\sigma, \mu)$ be a fuzzy graph on $G^{*}$. The total degree of a vertex $u \in V$ is defined by $\operatorname{td}_{\mathrm{G}}(\mathrm{u})=\Sigma \mathrm{u} \neq \mathrm{v} \mu(\mathrm{v}, \mathrm{u})+\sigma(\mathrm{u})$

Definition 2.6: An Intuitionistic fuzzy graph is of the form $\mathrm{G}=\langle\mathrm{V}, \mathrm{E}\rangle$ where

(i) $\mathrm{V}=\{\mathrm{v} 1, \mathrm{v} 2, \ldots, \mathrm{vn}\}$ such that $\mu_{1}: \mathrm{V} \rightarrow[0,1]$ and $\gamma_{1}: \mathrm{V} \rightarrow[0,1]$ denote the degree of membership and nonmembership of the element vi $\in \mathrm{V}$, respectively, and $0 \leq \mu_{1}$ (vi) $+\gamma_{1}$ (vi) $\leq 1$ for every vi $\epsilon \mathrm{V},(\mathrm{i}=1,2, \ldots \ldots \mathrm{n})$,

(ii) $\mathrm{E} \subseteq \mathrm{V} \mathrm{x} \mathrm{V}$ where $\mu_{2}: \mathrm{VxV} \rightarrow[0,1]$ and $\gamma_{2}: \mathrm{VxV} \rightarrow[0,1]$ are such that $\mu_{2}(\mathrm{vi}, \mathrm{vj}) \leq \min \left[\mu_{1}(\mathrm{vi}), \mu_{1}(\mathrm{vj})\right]$ and $\gamma_{2}(\mathrm{vi}, \mathrm{vj}) \leq \max \left[\gamma_{1}(\mathrm{vi}), \gamma_{1}(\mathrm{vj})\right]$ and $0 \leq \mu_{2}(\mathrm{vi}, \mathrm{vj})+\gamma_{2}(\mathrm{vi}, \mathrm{vj}) \leq 1$ for every $(\mathrm{vi}, \mathrm{vj}) \in \mathrm{E},(\mathrm{i}, \mathrm{j}=1,2, \ldots \ldots \mathrm{n})$

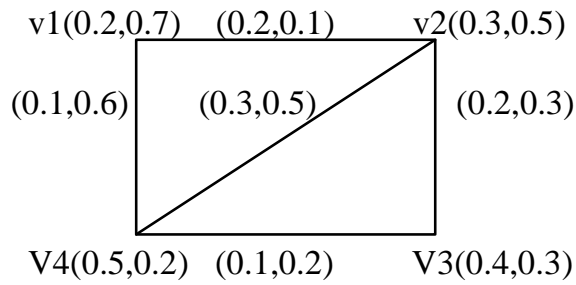

Fig 1: Intuitionistic Fuzzy Graph 
Definition 2.7:Let $\mathrm{G}=\langle\mathrm{V}$,E $>$ be an IFG. Then the degree of a vertex $\mathrm{v}$ is defined by $\mathrm{d}(\mathrm{v})=(\mathrm{d} \mu(\mathrm{v}), \mathrm{d} \gamma(\mathrm{v}))$ where $\mathrm{d} \mu(\mathrm{v})=\Sigma \mathrm{u} \neq \mathrm{v} \mu_{2}(\mathrm{v}, \mathrm{u})$ and $\mathrm{d} \gamma(\mathrm{v})=\Sigma \mathrm{u} \neq \mathrm{v} \gamma_{2}(\mathrm{v}, \mathrm{u})$.

Definition 2.8: The minimum degree of $\mathrm{G}$ is $\delta(\mathrm{G})=(\delta \mu(\mathrm{G}), \delta \gamma(\mathrm{G}))$ where $\delta \mu(\mathrm{G})=\Lambda\{\mathrm{d} \mu(\mathrm{v}) / \mathrm{v} \in \mathrm{V}\}$ and $\delta \gamma(\mathrm{G})=\Lambda\{\mathrm{d} \gamma(\mathrm{v}) / \mathrm{v} \in \mathrm{V}\}$

Definition 2.9: The maximum degree of $\mathrm{G}$ is $\Delta(\mathrm{G})=(\Delta \mu(\mathrm{G}), \Delta \gamma(\mathrm{G}))$ where $\Delta \mu(\mathrm{G})=\mathrm{V}\{\mathrm{d} \mu(\mathrm{v}) / \mathrm{v} \in \mathrm{V}\}$ and $\Delta \gamma(\mathrm{G})=\mathrm{V}\{\mathrm{d} \gamma(\mathrm{v}) / \mathrm{v} \in \mathrm{V}\}$

Definition 2.10: An edge e $=(x, y)$ of an IFG $G=\langle\mathrm{V}, \mathrm{E}\rangle$ is called an effective edge if $\mu_{2}(\mathrm{x}, \mathrm{y})=\mu_{1}(\mathrm{x}) \Lambda \mu_{1}(\mathrm{y})$ and $\gamma_{2}(\mathrm{x}, \mathrm{y})=\gamma_{1}(\mathrm{x}) \mathrm{V} \gamma_{1}(\mathrm{y})$.

Definition 2.11: An Intuitionistic fuzzy graph is complete if $\mu_{2 \mathrm{ij}}=\min \left(\mu_{1 \mathrm{i}}, \mu_{1 \mathrm{j}}\right)$ and $\gamma_{2 i j}=\max \left(\gamma_{2 \mathrm{i}}, \gamma_{2 \mathrm{j}}\right)$ for all $(\mathrm{vi}, \mathrm{vj}) \in \mathrm{V}$.

Definition 2.12: The total degree of a vertex ' $u$ ' is defined as $\operatorname{td}(u)=\left(\operatorname{td}_{\mu}(u), \operatorname{td}_{\gamma}(u)\right)$, where $\operatorname{td}_{\mu}(\mathrm{u})=\Sigma \mathrm{u} \neq \mathrm{v} \mu_{2}(\mathrm{u}, \mathrm{v})+\mu_{1}(\mathrm{u})$ and $\operatorname{td}_{\gamma}(\mathrm{u})=\Sigma \mathrm{u} \neq \mathrm{v} \gamma_{2}(\mathrm{u}, \mathrm{v})+\gamma_{1}(\mathrm{u})$

Definition 2.13: An IFG $\mathrm{H}=<\mathrm{V}$ ', E' $>$ is said to be an Intuitionistic fuzzy subgraph (IFSG) of the IFG, $\mathrm{G}=\langle\mathrm{V}, \mathrm{E}\rangle$ if $\mathrm{V}^{\prime} \subseteq \mathrm{V}$ and $\mathrm{E}^{\prime} \subseteq \mathrm{E}$. In other words, if $\mu_{1 \mathrm{i}}{ }^{\prime} \leq \mu_{1 \mathrm{i}} ; \gamma_{1 \mathrm{i}}{ }^{\prime} \geq \gamma_{1 \mathrm{i}}$ and $\mu_{2 \mathrm{ij}}{ }^{\prime} \leq \mu_{2 \mathrm{ij}} ; \gamma_{2 \mathrm{ij}}{ }^{\prime} \geq \gamma_{2 \mathrm{ij}}$ for every $\mathrm{i}, \mathrm{j}=1,2 \ldots \ldots \ldots$.

Definition 2.14: The complement of an IFG G $=\langle\mathrm{V}, \mathrm{E}\rangle$ is denoted by $\bar{G}=\langle\bar{V}, \bar{E}\rangle$ and is defined as i) $\bar{\mu}_{1}(u)=\mu_{1}(\mathrm{u})$ and $\bar{\gamma}_{1}(u)=\gamma_{1}(\mathrm{u})$ for every $u \in \mathrm{V}$.

ii) $\bar{\mu}_{2}(\mathrm{u}, \mathrm{v})=\mu_{1}(\mathrm{u}) \Lambda \mu_{1}(\mathrm{v})-\mu_{2}(\mathrm{u}, \mathrm{v})$ and $\bar{\gamma}_{2}(\mathrm{u}, \mathrm{v})=\gamma_{1}(\mathrm{u}) \mathrm{V} \gamma_{1}(\mathrm{v})-\gamma_{2}(\mathrm{u}, \mathrm{v})$ for all $\left.(\mathrm{u}, \mathrm{v})\right) \in \mathrm{E}$.

Definition 2.15: An Intuitionistic fuzzy graph $\mathrm{G}=\langle\mathrm{V}, \mathrm{E}\rangle$ is said to be regular, if every vertex adjacent to vertices withsame degree.

Example:

Let $\mathrm{G}=\langle\mathrm{V}, \mathrm{E}\rangle$ be a IFG. The membership and non-membership values of $\mathrm{G}$ are defined by, $\left(\mu_{1}(\mathrm{u}), \gamma_{1}(\mathrm{u})\right)=(0.4,0.5),\left(\mu_{1}(\mathrm{v}), \gamma_{1}(\mathrm{v})\right)=(0.5,0.5),\left(\mu_{1}(\mathrm{w}), \gamma_{1}(\mathrm{w})\right)=(0.5,0.3),\left(\mu_{1}(\mathrm{x}), \gamma_{1}(\mathrm{x})\right)=(0.5,0.4)$, and $\left(\mu_{2}(\mathrm{u}, \mathrm{v}), \gamma_{2}(\mathrm{u}, \mathrm{v})\right)=(0.3,0.3),\left(\mu_{2}(\mathrm{v}, \mathrm{w}), \gamma_{2}(\mathrm{v}, \mathrm{w})\right)=(0.4,0.2),\left(\mu_{2}(\mathrm{w}, \mathrm{x}), \gamma_{2}(\mathrm{w}, \mathrm{x})\right)=(0.3,0.3)$, $\left(\mu_{2}(\mathrm{x}, \mathrm{u}), \gamma_{2}(\mathrm{x}, \mathrm{u})\right)=(0.4,0.2)$. Here $\mathrm{G}$ is regular.

\section{Irregular Intuitionistic fuzzy graphs}

Definition 3.1: Let $G=\langle V, E\rangle$ be IFG. Then $G$ is irregular, if there is a vertex which is adjacent to vertices with distinct degrees.

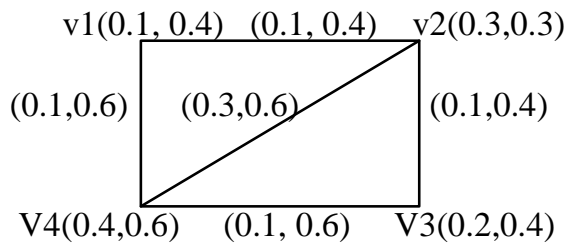

Fig- 2:Intuitionistic fuzzy graph

Here v1 adjacent to v2 and v4 which are having distinct degrees, So G is Irregular IFG.

Definition 3.3: Let $G=<\mathrm{V}, \mathrm{E}>$ be a connected IFG. G is said to be a neighbourly irregular Intuitionistic fuzzy graph if every two adjacent vertices of $G$ have distinct degree.

Example:

In Fig -2, $\mathrm{d}(\mathrm{v} 1)=(0.2,1) ; \mathrm{d}(\mathrm{v} 2)=(0.4,1.4) ; \mathrm{d}(\mathrm{v} 3)=(0.2,1) ; \mathrm{d}(\mathrm{v} 4)=(0.5,1.8)$

The adjacent vertices v1, v2 and v4 are having distinct degrees, Also the adjacent vertices v2, v3 and v4 are having distinct degrees. (i.e) $\mathrm{G}$ is also neighbourly irregular Intuitionistic fuzzy graph.

Definition 3.4: Let $\mathrm{G}=\langle\mathrm{V}, \mathrm{E}\rangle$ be a connected IFG. Then, $\mathrm{G}$ is said to be a highly irregular IFG if every vertex of $\mathrm{G}$ is adjacent to vertices with distinct degrees

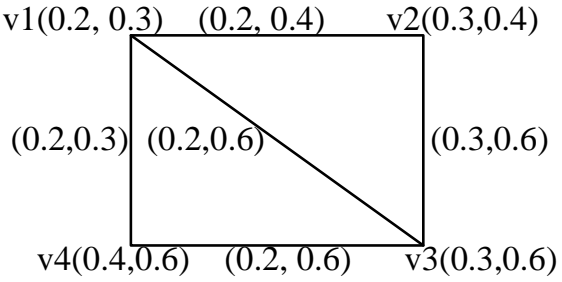

Fig-3: Highly Irregular Intuitionistic fuzzy graph

Here, Every vertex of IFG is adjacent to vertices with distinct degrees. 


\section{Proposition 3.5}

A highly irregular IFG need not be a neighbourly irregular IFG.

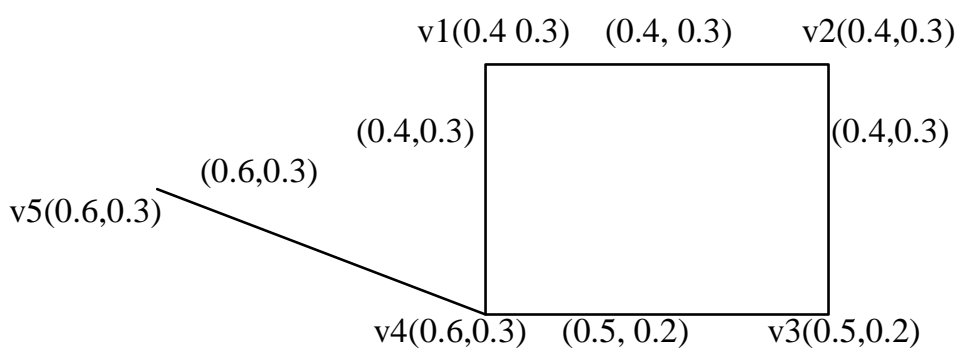

Fig-4: Highly Irregular Intuitionistic fuzzy graph But not neighbourly irregular IFG.

\section{Proposition 3.6:}

A neighbourly irregular IFG need not be a highly irregular IFG.

Example:

In Fig -2, $\mathrm{d}(\mathrm{v} 1)=(0.2,1) ; \mathrm{d}(\mathrm{v} 2)=(0.4,1.4) ; \mathrm{d}(\mathrm{v} 3)=(0.2,1) ; \mathrm{d}(\mathrm{v} 4)=(0.5,1.8)$

i.e) neighbourly irregular IFG, But, for the vertex v2, adjacent vertices, $d(v 1)=d(v 3)$.

So, is not Highly Irregular IFG.

\section{Theorem 3.7}

Let $\mathrm{G}=\langle\mathrm{V}, \mathrm{E}>$ is highly irregular intuitionistic fuzzy graph and neighbourly irregular intuitonistic fuzzy graph if and only if the degrees of all vertices of $G$ are distinct.

Proof:

Let, $\mathrm{G}$ be the IFG with $\mathrm{n}$ vertices $\mathrm{v} 1, \mathrm{v} 2, \ldots, \mathrm{vn}$.

Now, Suppose G is highly irregular and neighbourly irregular IFG. Let the adjacent vertices of v1 be v2, $\mathrm{v} 3, \ldots, \mathrm{vn}$ with degrees $\left(\mathrm{c}_{2}, \mathrm{k}_{2}\right),\left(\mathrm{c}_{3}, \mathrm{k}_{3}\right), \ldots,\left(\mathrm{c}_{\mathrm{n}}, \mathrm{k}_{\mathrm{n}}\right)$ respectively.

Since $\mathrm{G}$ is highly irregular, $\mathrm{c}_{2} \neq \mathrm{c}_{3} \neq, \ldots, \neq \mathrm{cn}$. Also $\mathrm{k}_{2} \neq \mathrm{k}_{3} \neq, \ldots, \neq \mathrm{kn}$.

(i.e) $d(v 1)$ is not either of $\left(c_{2}, k_{2}\right),\left(c_{3}, k_{3}\right), \ldots,\left(c_{n}, k_{n}\right)$

Therefore, the degrees of all vertices of $\mathrm{G}$ are distinct

Conversely, Assume that the degrees of all vertices of $\mathrm{G}$ are distinct.

Which implies that, every two adjacent vertices have distinct degrees and to every vertex, the adjacent vertices have distinct degrees.

That is, $\mathrm{G}$ is neighbourly irregular and highly irregular IFG.

\section{Proposition 3.8:}

If a IFG $\mathrm{G}=\left\langle\mathrm{V}, \mathrm{E}>\right.$ is neighbourly irregular,then $\mathrm{G}^{\mathrm{c}}$ is need not be neighbourly irregular

\section{Example 3.9:}

Let $\mathrm{G}=\left\langle\mathrm{V}, \mathrm{E}>\right.$ be a IFG. Let, $\left(\mu_{1}(\mathrm{u}), \gamma_{1}(\mathrm{u})\right)=(0.3,0.4),\left(\mu_{1}(\mathrm{v}), \gamma_{1}(\mathrm{v})\right)=(0.4,0.5),\left(\mu_{1}(\mathrm{w}), \gamma_{1}(\mathrm{w})\right)=(0.5,0.3)$, $\left(\mu_{1}(\mathrm{x}), \gamma_{1}(\mathrm{x})\right)=(0.4,0.3)$, and $\left(\mu_{2}(\mathrm{u}, \mathrm{v}), \gamma_{2}(\mathrm{u}, \mathrm{v})\right)=(0.1,0.3),\left(\mu_{2}(\mathrm{v}, \mathrm{w}), \gamma_{2}(\mathrm{v}, \mathrm{w})\right)=(0.3,0.4)$,

$\left(\mu_{2}(w, x), \gamma_{2}(w, x)\right)=(0.3,0.2),\left(\mu_{2}(x, u), \gamma_{2}(x, u)\right)=(0.2,0.3)$.

Here, $\mathrm{d}(\mathrm{u})=(0.3,0.6) ; \mathrm{d}(\mathrm{v})=(0.4,0.7) ; \mathrm{d}(\mathrm{w})=(0.6,0.6) ; \mathrm{d}(\mathrm{x})=(0.5,0.5)$

But in $\mathrm{G}^{\mathrm{c}}$,

$\left(\mu_{2}(\mathrm{u}, \mathrm{v}), \gamma_{2}(\mathrm{u}, \mathrm{v})\right)=(0.2,0.2),\left(\mu_{2}(\mathrm{v}, \mathrm{w}), \gamma_{2}(\mathrm{v}, \mathrm{w})\right)=(0.1,0.1),\left(\mu_{2}(\mathrm{w}, \mathrm{x}), \gamma_{2}(\mathrm{w}, \mathrm{x})\right)=(0.1,0.1)$

$\left(\mu_{2}(\mathrm{x}, \mathrm{u}), \gamma_{2}(\mathrm{x}, \mathrm{u})\right)=(0.1,0.1),\left(\mu_{2}(\mathrm{u}, \mathrm{w}), \gamma_{2}(\mathrm{u}, \mathrm{w})\right)=(0.3,0.4),\left(\mu_{2}(\mathrm{x}, \mathrm{v}), \gamma_{2}(\mathrm{x}, \mathrm{v})\right)=(0.4,0.5)$.

Here, $\mathrm{d}(\mathrm{u})=\mathrm{d}(\mathrm{x})=(0.6,0.7)$

That is $\mathrm{G}^{\mathrm{c}}$ is not neighbourly irregular IFG.

\section{Proposition 3.10:}

The converse of the above result is not true. (i.e) If a IFG $G=\langle\mathrm{V}, \mathrm{E}>$ is not neighbourly irregular, then its complement need not neighbourly irregular.

\section{Example 3.11:}

Let $\mathrm{G}=\left\langle\mathrm{V}, \mathrm{E}>\right.$ be a IFG. We define $\mathrm{G}$ as, $\left(\mu_{1}(\mathrm{u}), \gamma_{1}(\mathrm{u})\right)=(0.5,0.4),\left(\mu_{1}(\mathrm{v}), \gamma_{1}(\mathrm{v})\right)=(0.4,0.2)$, $\left(\mu_{1}(\mathrm{w}), \gamma_{1}(\mathrm{w})\right)=(0.5,0.3),\left(\mu_{1}(\mathrm{x}), \gamma_{1}(\mathrm{x})\right)=(0.4,0.3),\left(\mu_{1}(\mathrm{y}), \gamma_{1}(\mathrm{y})\right)=(0.6,0.3)$ and $\left(\mu_{2}(\mathrm{u}, \mathrm{v}), \gamma_{2}(\mathrm{u}, \mathrm{v})\right)=(0.4,0.4)$, $\left(\mu_{2}(u, w), \gamma_{2}(u, w)\right)=(0.1,0.3),\left(\mu_{2}(u, x), \gamma_{2}(u, x)\right)=(0.2,0.2),\left(\mu_{2}(u, y), \gamma_{2}(u, y)\right)=(0.5,0.3)$, 
$\left(\mu_{2}(v, w), \gamma_{2}(v, w)\right)=(0.3,0.2),\left(\mu_{2}(w, x), \gamma_{2}(w, x)\right)=(0.3,0.1),\left(\mu_{2}(x, y), \gamma_{2}(x, y)\right)=(0.2,0.3)$

Clearly $\mathrm{G}$ and $\mathrm{G}^{\mathrm{c}}$ are not neighbourly irregular IFG, since $\mathrm{d}(\mathrm{x})=\mathrm{d}(\mathrm{y})=\mathrm{d}(\mathrm{v})=\mathrm{d}(\mathrm{w})=(0.7,0.6)$ in $\mathrm{G}$ and $\mathrm{d}(\mathrm{w})=\mathrm{d}(\mathrm{y})=(1.1,0.7)$; Also $\mathrm{d}(\mathrm{v})=\mathrm{d}(\mathrm{x})=(0.9,0.7)$ which are adjacent vertices in $\mathrm{G}^{\mathrm{c}}$.

\section{Remark:}

(i) A complete IFG need not be neighbourly irregular

(ii) In Fuzzy case, $\mathrm{G}=\langle\mathrm{V}, \mathrm{E}\rangle$ is neighbourly irregular, then $\mathrm{G}^{\mathrm{c}}$ always not neighbourly irregular. But in Intuitionistic Fuzzy case, we can’t say always, but may not be neighbourly irregular.

\section{Totally Irregular Intuitionistic Fuzzy Graphs}

Definition 4.1: Let $\mathrm{G}=\langle\mathrm{V}, \mathrm{E}\rangle$ be a IFG. Then $\mathrm{G}$ is totally irregular, if there is a vertex which is adjacent to vertices with distinct total degrees.

Example

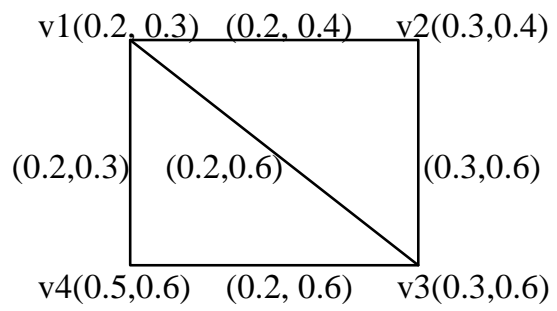

Fig-5: Totally Irregular IFG

Definition 4.2: If every two adjacent vertices of a IFG $, G=<V, E>$ have distinct total degree, then $\mathrm{G}$ is said to be a neighbourly total irregular IFG.

Example:

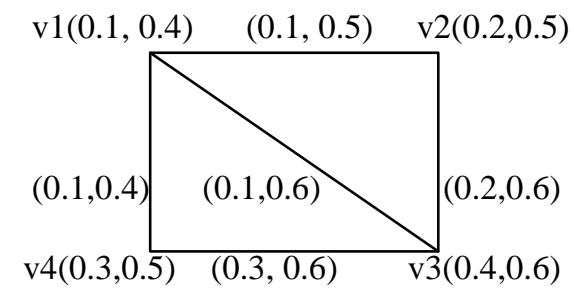

.Proposition 4.3:

Fig-6: Neibourly totally irregular IFG

A neighbourly irregular Intuitionistic fuzzy graph need not be a neighbourly total irregular IFG.

Example:

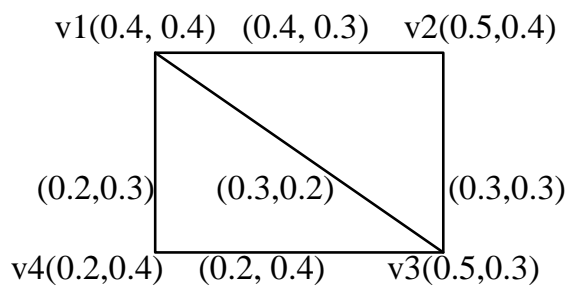

Proposition 4.5:

Fig-7: Neibourly irregular IFG but not total Irregular

A neighbourly total irregular fuzzy graph need not be a neighbourly irregular fuzzy graph

Example:

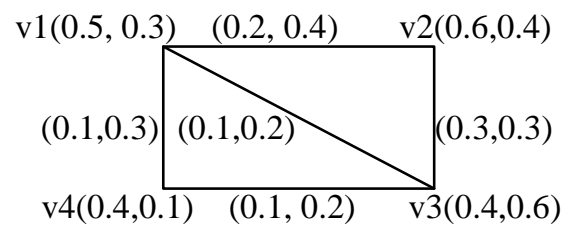

Fig-8: Neighbourly total irregular IFG but not neighbouly Irregular 


\section{Theorem 4.6:}

Let $\mathrm{G}=\langle\mathrm{V}$, E $\rangle$ be IFG. If $\mathrm{G}$ is neighbourly irregular and $\mu_{1}$ and $\gamma_{1}$ are constant functions, then $\mathrm{G}$ is a neighbourly total irregular IFG.

\section{Proof:}

Assume $\mathrm{G}=\langle\mathrm{V}, \mathrm{E}\rangle$ is neighbourly Irregular IFG. i.e) the degrees of every two adjacent vertices are distinct.

Consider two adjacent vertices $\mathrm{v} 1$ and $\mathrm{v} 2$ with distinct degrees say $\left(\mathrm{c}_{1}, \mathrm{c}_{2}\right)$ and $\left(\mathrm{k}_{1}, \mathrm{k}_{2}\right)$.

Then $\mathrm{d}(\mathrm{v} 1)=\left(\mathrm{c}_{1}, \mathrm{c}_{2}\right)$ and $\mathrm{d}(\mathrm{v} 2)=\left(\mathrm{k}_{1}, \mathrm{k}_{2}\right)$ where $\mathrm{c}_{1} \neq \mathrm{k}_{1}, \mathrm{c}_{2} \neq \mathrm{k}_{2}$.

Also assume $\mu_{1}(\mathrm{v} 1)=\mu_{1}(\mathrm{v} 2)=\mathrm{a}$ and $\gamma_{1}(\mathrm{v} 1)=\gamma_{1}(\mathrm{v} 2)=\mathrm{b} ; \mathrm{a}, \mathrm{b}$ are constant and in $[0,1]$.

Therefore, $\operatorname{td}_{\mu}(\mathrm{v} 1)=\mathrm{d}_{\mu}(\mathrm{v} 1)+\mu_{1}(\mathrm{v} 1)=\mathrm{c}_{1}+\mathrm{a} ; \operatorname{td}_{\mu}(\mathrm{v} 2)=\mathrm{d}_{\mu}(\mathrm{v} 2)+\mu_{1}(\mathrm{v} 2)=\mathrm{k}_{1}+\mathrm{a}$

To prove, $\operatorname{td}_{\mu}(v 1) \neq \operatorname{td}_{\mu}(v 2)$

Suppose, $\operatorname{td}_{\mu}(\mathrm{v} 1)=\operatorname{td}_{\mu}(\mathrm{v} 2)$

$\mathrm{c}_{1}+\mathrm{a}=\mathrm{k}_{1}+\mathrm{a} \Rightarrow \mathrm{c}_{1}-\mathrm{k}_{1}=\mathrm{a}-\mathrm{a}=0 \Rightarrow \mathrm{c}_{1}=\mathrm{k}_{1}$ which is contradiction to $\mathrm{c}_{1} \neq \mathrm{k}_{1}$

Therefore the total $\mu$-degrees of vertices are distinct.

Similarly, If $\gamma_{1}$ is constant, the total $\gamma$-degrees of vertices are distinct.

That is $\mathrm{G}$ is neighbourly total irregular IFG.

\section{Theorem 4.7:}

Let $\mathrm{G}=\langle\mathrm{V}, \mathrm{E}>$ be a neighbourly total irregular IFG and $\mu 1$ and $\gamma 1$ are constant functions, then $\mathrm{G}$ is a neighbourly irregular IFG

\section{Proof:}

Assume $\mathrm{G}=\langle\mathrm{V}, \mathrm{E}\rangle$ is neighbourly total Irregular IFG. i.e) the total degrees of every two adjacent vertices are distinct.

Consider two adjacent vertices v1 and v2 with distinct degrees say $\left(\mathrm{c}_{1}, \mathrm{c}_{2}\right)$ and

$\left(\mathrm{k}_{1}, \mathrm{k}_{2}\right)$. Then $\mathrm{d}(\mathrm{v} 1)=\left(\mathrm{c}_{1}, \mathrm{c}_{2}\right)$ and $\mathrm{d}(\mathrm{v} 2)=\left(\mathrm{k}_{1}, \mathrm{k}_{2}\right)$ where $\mathrm{c}_{1} \neq \mathrm{k}_{1}, \mathrm{c}_{2} \neq \mathrm{k}_{2}$.

Also, $\mu_{1}(\mathrm{v} 1)=\mu_{1}(\mathrm{v} 2)=\mathrm{a}$ and $\gamma_{1}(\mathrm{v} 1)=\gamma_{1}(\mathrm{v} 2)=\mathrm{b} ; \mathrm{a}, \mathrm{b}$ are constant and in $[0,1]$

Assume $\operatorname{td}_{\mu}(\mathrm{v} 1) \neq \mathrm{td}_{\mu}(\mathrm{v} 2)$

To prove , $\mathrm{d}_{\mu}(\mathrm{v} 1) \neq \mathrm{d}_{\mu}(\mathrm{v} 2)$

As $\operatorname{td}_{\mu}(\mathrm{v} 1) \neq \mathrm{d}_{\mu}(\mathrm{v} 2)$

$$
\mathrm{c}_{1}+\mathrm{a} \neq \mathrm{k}_{1}+\mathrm{a} \Rightarrow \mathrm{c}_{1} \neq \mathrm{k}_{1}
$$

Therefore the $\mu$-degrees of adjacent vertices are distinct if $\mu 1$ is constant function.

Similarly, we prove If $\gamma_{1}$ is constant, the $\gamma$-degrees of adjacent vertices are distinct.

i.e) $c_{2}+b \neq k_{2}+b \Rightarrow c_{2} \neq k_{2}$

This is true for all the pair of adjacent vertices

Therefore $\mathrm{G}$ is neighbourly irregular IFG.

\section{Proposition 4.8:}

Let $\mathrm{G}=\langle\mathrm{V}, \mathrm{E}\rangle$ be neighbourly irregular IFG then Intuitionistic fuzzy subgraph $\mathrm{H}$ of $\mathrm{G}$ need not be neighbourly irregular IFG.

Example:
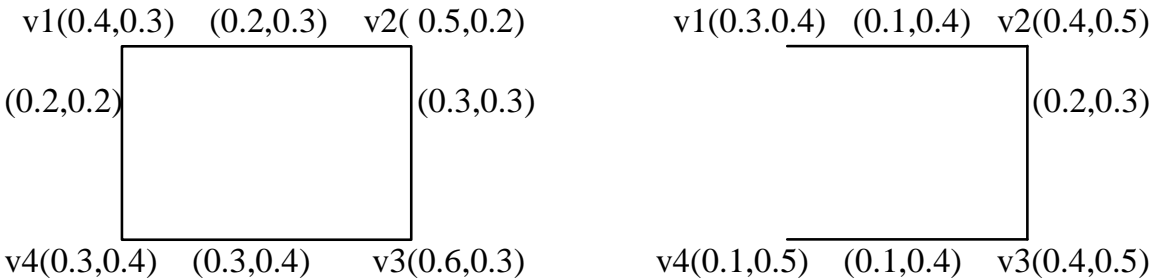

Fig-9: Neighbourly irregular IFG G

Fig-10: Not neighbourly Irregular Subgraph of G

\section{References}

[1]. Atanassov KT. Intuitionistic fuzzy sets: theory and applications. Physica, New York, 1999.

[2]. Harary,F., Graph Theory, Addition Wesley, Third Printing, October 1972

[3]. NagoorGani. A and Latha .S.R., On Irregular Fuzzy Graphs, Applied Mathematical Sciences, Vol.6, 2012, no.11,517-523.

[4]. Nagoor Gani. A and Shajitha Begum.S, Degree, Order and Size in Intuitionistic Fuzzy Graphs, International Journal of Algorithms, Computing and Mathematics,(3)3 (2010).

[5]. Parvathi, R. and Karunambigai, M.G., Intuitionistic Fuzzy Graphs, Computational Intelligence, Theory and applications, International Conference in Germany, Sept 18 -20, 2006.

[6]. Zimmermann, H.J., Fuzzy Set Theory and its Applications, Kluwer-Nijhoff,Boston, 1985. 